\title{
Transparency in higher education: An investigation of University students' perceptions in Italy and Russia
}

\author{
Alexander Porshnev*, Rosa Cera**, Marta Sinclair***, \\ Alessandro Antonietti ${ }^{\circ}$ \\ *National Research University Higher School of Economics, \\ MyasnitskayaUlitsa, 20, 101000, Moscow, Russia \\ e-mail: aporshnev@hse.ru; \\ **Department of Humanistic Studies, University of Foggia, \\ Via Arpi, 176, 71121, Foggia, Italy \\ e-mail: rosa.cera@unifg.it; \\ *** Griffith Business School, Griffith University, Nathan campus, \\ KesselsRoad, Nathan Brisbane, Queensland 4111, Australia \\ e-mail: m.sinclair@griffith.edu.au; \\ ${ }^{\circ}$ Department of Psychology, Catholic University of the Sacred Heart, \\ L.go Gemelli, 1, 201123 Milan, Italy \\ e-mail: alessandro.antonietti@unicatt.it.
}

Ricevuto: 23.11.2020 - Accettato: 07.04.2021

Pubblicato online: 16.11 .2021

\begin{abstract}
The primary purpose of this research is to investigate students' perceptions of the presence of transparency in their university teaching/learning processes. Effects of transparency in achievement, motivation, and anxiety were explored from the perspective of teachers', one's own, and peers' behaviour. The secondary objective of the study was to create a valid tool for investigating "transparency" perception in university educational practices, based on the theoretical assumption that transparency reduces performance anxiety, stimulates study motivation, and represents a universal construct across universities, countries, cultures and courses of study. A sample of 439 undergraduates from leading research universities in Russia and Italy completed self-report scales and reported demographic data. The scales showed internal consistency and structural invarian-
\end{abstract}

A. Porshnev et al. / Ricerche di Psicologia, 2021, Vol. 44 ISSN 0391-6081, ISSNe 1972-5620, Doi: 10.3280/rip2021 oa12852 
ce in both countries. Research results confirmed the hypothesis from which the investigation originated. Based on the findings, essential tips for future investigations of transparency perception at universities have been developed.

Keywords: transparency; perceptions; student/teacher and peer relationships; intrinsic motivation; anxiety; academic success.

The research topic of the article was jointly decided by the authors and all parts of the article were jointly revised. The following paragraphs are specifically attributable to Rosa Cera: Introduction; "Transparency" in Russian and Italian higher education, Students' perception of transparency in educational practices; Transparency, Motivation and Anxiety in Learning Performance; Educational Implications.

\section{Introduction}

The application of "transparency" in the educational context not only assumes participation of students in the planning stages of an educational project, it also requires their willingness to express appreciation of teachers' skills, their ability to create links between different disciplines, and the availability of teachers to listen to students' needs and criticisms (Winkelmes, Copeland, Jorgensen, Sloat, Smedley, Pizor, Jhnson, \& Jalene, 2015). The educational paths based on the concept of "transparency" allow students to become aware of their learning process, develop cognitive and metacognitive skills, and be the true architect of their own learning (Authors, 2013; Cohen, 1980; Dunlosky \& Metcalfe, 2009). In addition to its impact on the planning of study activities, the principle of "transparency" is also essential in the evaluation activities as it allows teachers and students to identify connections between teaching and learning variables and provides valid indications to those who bear responsibility within educational institutions in general (Jönsson \& Prins, 2019; Pasupathy \& Siwatu, 2014). Furthermore, "transparency" in online educational practices helps to mitigate some negative effects that may depend on the virtual classroom (Howard, Winkelmes \& Shegog, 2017), such as lack of attention or poor motivation to learn. The results of "transparency" in higher education are therefore positive in both face-toface and distance learning, as suggested by academic achievements in remote teaching. 
In this research, to investigate the perception of "transparency" in educational practices, we interviewed students enrolled in universities that have different characteristics, as we believe that transparency is universal across disciplines and contexts. The Catholic University of the Sacred Heart of Milan (Italy), National Research University Higher School of Economics (Russia) and the University of Foggia (Italy) are not only in different geographical locations, each institution also exhibits unique characteristics, such as a particular history and culture, different enrolment numbers, and a different (public or private) sector. Despite these differences, we believe that "transparency" in educational practices is universal as it mainly depends on teachers' ability to involve students in the planning and implementation of study courses, on students' perception of their own capability to be transparent in sharing educational processes and how they perceive transparency in the relationship among peers. Our view that "transparency" goes beyond geographical, social and cultural boundaries builds on the foundation established in the Bologna Process (Bologna Declaration, Bologna Process, 1999). In this process learning and teaching are considered key areas to be reformed according to the principle of quality assurance, enabling students to play an active and highly involved role (European Commission/EACEA/Eurydice, 2018).

Although "transparency" is sometimes observed, it is rarely measured. As a result, no tools to capture it in a systematic manner are available. For this reason, our research explores a tool for investigating transparency in university teaching and learning activities. Specifically, we study the relationship with learning motivation, anxiety and academic success under the premise that transparency in the relationship between students and teachers and in teaching activities in general stimulates motivation to learn and reduces performance anxiety.

\section{"Transparency" in Russian and Italian higher education}

Knowledge of how students perceive "transparency" in educational practices helps teachers to reflect on the importance of the quality of communication in teaching/learning processes. The quality of communication depends a lot on university and academic freedom and autonomy. As for Russia, the progress made in recent years in achieving greater academic autonomy is considerable (Gavrilyuk, Nosova, Susloparova \& Lakhno, 2015). A type of academic autonomy also ensures greater academic freedom both in the choice of teaching methods and in research. However, not all Russian teachers are able to use academic freedom and autonomy, as they have long been linked to values dictated by the Soviet 
socio-cultural context. A wise management of the acquired freedom by teachers requires adding "transparent" educational practices that can be considered and perceived also by students. When there is a greater perception of "transparency" it means, in fact, that "falsification" of freedom in education can be avoided, eliminating situations in which students pretend to exercise a free choice and teachers pretend to make decisions and provide students with opportunity to do the same (Yefimov \& Krasnoyarsk, 2012).

The application of "transparency" principle in the educational field depends very much on the ability of teachers to continuously update their skills and to "innovatively self-change". In Europe, not all universities can enjoy the same academic autonomy and freedom, however much progress has been made through the Bologna Process, a globally respected political initiative that established the European Higher Education Area. In the Bologna Process, European countries have recognized the importance of implementing reforms in higher education related to specific values, such as freedom of expression, institutional autonomy, academic freedom and the free movement of students and academics. However, not all European countries have respected these values. In Italy, academic freedom is a constitutional right, although this has not always guaranteed greater "transparency" in educational practices. Such transparency is entrusted to the teacher's ability to use teaching and communication methods aimed at developing students' critical and creative thinking, as well as assessment methods designed to make monitoring and evaluation criteria explicit.

Hattie's "visible learning approach" (Hattie, 2012; Hattie \& Yates, 2014) emphasizes, for example, the importance of assessment being explicit. Evaluation is "transparent" when students know the form and purpose of the evaluation itself, which is also linked to the choice of learning strategies by students. Hence, students are willing to vary their learning strategies and improve them if they feel they have been assessed in a "transparent" and "fair" way. Timely knowledge, trust and communication skills form therefore the basis of a "transparent" learning process. Making the teaching/learning process explicit and clear helps students to feel more involved in achieving the learning objectives and reduces their tendency to abandon studies (Winkelmes, 2016). Only if learning objectives become "transparent", the methods and tools of learning, the way in which the knowledge and skills are acquired, can be applied to the real world of work. This ensures not only the academic success of the student but also the professional one (Winkelmes, Boye \& Tapp, 2019). Transparency in higher education depends not only on academic autonomy, 
but also on the teacher's ability to appeal to that autonomy in order to plan, in collaboration with students, valid educational paths for the development of specific skills such as learning to learn.

\section{Students'perception of transparency in educational practices}

To investigate the perception of average transparency within the study program in which students are enrolled, it is important to pay close attention to the kind of relationships that teachers and students create. Students' perceptions of their teachers have been scientifically proven to exert important influences on how students approach learning and view overall satisfaction with their university experiences (Karpouza \& Emvalotis, 2019; Lennon, Riley \& Monk, 2018). In addition to their perception of transparency about how their teachers involve them in educational activities, it is also important to know how students perceive their involvement and cognitive commitment. Indeed, some studies have shown how students' perception of what they would have learned in the classroom predicted their engagement, which then predicted their learning (Jones \& Carter, 2019). This demonstrates how students' perceptions of empowerment (i.e. their ability to choose and make decisions) are particularly important in predicting their cognitive engagement. The third kind of students' perception of transparency, which has been also investigated in our research, concerns their relationship with peers. If students perceive, for example, that they are able to establish a relationship based on transparency and collaboration with their peers, they will be capable of a greater social and academic integration. The capacity for academic integration consists of the will (motivation) and the ability (e.g. cognitive skills) to belong to a group (Tinto, 1993). The perception of belonging to a group promotes, in turn, peer learning which is considered useful for sharing experiences and for a greater emotional support and esteem among students (Byl, Struyven, Meurs, Abelshausen, Vanwing, Engels, \& Lombaerts, 2016).

The three different areas of investigation of "transparency" in our research correspond to what was established in the Bologna Process, where students are considered co-creators of their educational experiences and are endowed with specific academic rights. In this respect, Saint-Petersburg State University is one of Russian universities that have pioneered empirical research about academic rights of students, demonstrating that the absence of a clear and transparent communication between teachers and students, and between students and administrative offices of the university, has often been the cause of students' unawareness of their academic rights (Romanova, Romanov, Maznichenko \& Oborin, 2018). The 
principles of the Bologna Process have guaranteed greater rights not only to students of Russian universities but also to those at European universities. In particular, the Quality Assurance System outlined in the Bologna Process has allowed Russian universities to define certain educational standards, so as to align Russian programs with European university programs (Karavaeva \& Zapryagaev, 2015).

\section{Transparency, Motivation and Anxiety in Learning Performance}

In addition to investigating the perception of transparency in the relationship between teachers and students, among peers and how students perceive to be transparent in their didactic activities, our research has assessed whether transparency influences intrinsic motivation and performance anxiety. Students tend to believe that they are more motivated if the learning setting is transparent. Furthermore, we could expect that students regard themselves as more self-transparent because they know their own motivation and strivings better than others. We might also expect that transparency leads to better learning outcomes thanks to its effect on motivation and to the adaptation of effective study strategies and approaches, which would result in less anxiety. For example, research has shown that transparency in assessment criteria positively influences student performance, helps reduce performance anxiety, and stimulates students to use self-regulated learning strategies (Jönsson \& Balan, 2017; Panadero \& Jönsson, 2013). Students get better results when they know what is expected of them (Winkelmes et al., 2016).

The "Transparency in Learning and Teaching" (TILT) project conducted at the University of Nevada and coordinated by Mary-Ann Winkelmes, demonstrated that when students understand the task, its purpose, and the criteria for evaluating their work, they are more motivated and find the work more relevant. Teaching practices based on the principles of "transparency" not only stimulate students' motivation to learn (Ellis \& Tod, 2015), but also contribute to reducing performance anxiety. Nevertheless, affective benefits can be produced by transparency because learning together with others helps the subject to contain his/her anxiety, reduces isolation, and elicits positive emotions (Jurkowski \& Hänze, 2015). In addition, peer learning contributes to the development of critical and creative thinking and enables students to successfully pass university exams (Loes \& Pascarella, 2017). 


\section{Research Aims}

Although we expect that learning at least at University level is universal and its perception invariant across different cultures, we could also expect that students in different countries are used to more or less "transparent" education environment. The same could be observed for usual attitude to transparency. According to the report of HRV government transparency index Italy scores 4.83 while Russia only 1.4 (HRV Transparency index, 2010).

So far, most studies of "transparency" at university level investigated communication and learning outcomes in a particular course (e.g. Winkelmes et al., 2015). Contrary to that, our study focuses on students' perceptions of learning-related communication in general, not limited to a specific course. The investigation draws on the following model of perception: teacher, peers, and self (see Fig. 1).

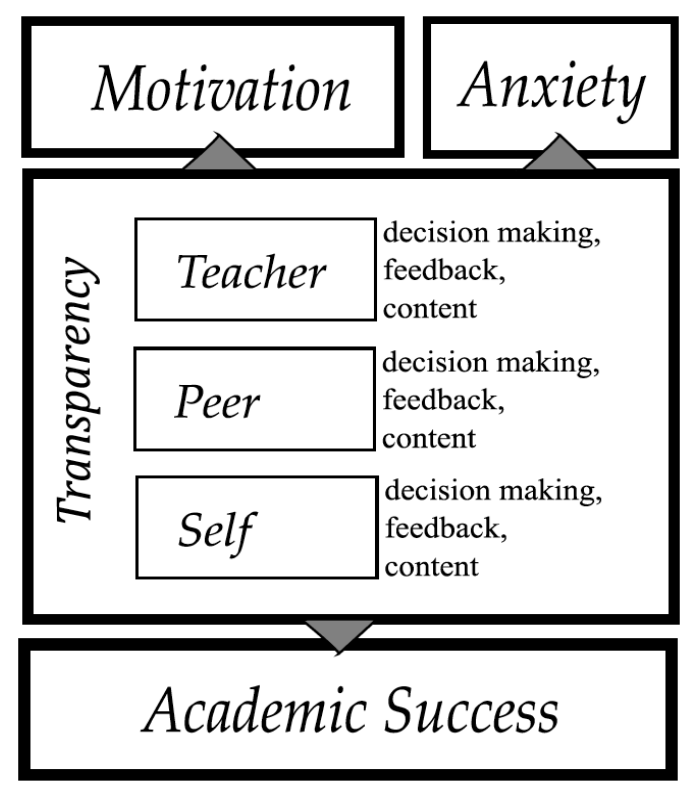

Fig.1 - Transparency Model and its Relationship with Learning Dimensions

The survey developed for this study has a twofold objective. The primary goal is to understand the perception that students have of the presence of transparency in their university teaching/learning processes. The supporting goal is methodological, that is, to evaluate if the tools used to capture the concepts are reliable. As outlined earlier, the survey explored 
students' perceptions of transparency in three specific aspects of the teaching/learning process: teacher-student relationship, peer relationship, and self-directed didactic activities. As a corollary, the aim was to find whether transparency-inspired didactic activities are associated with students' grades, motivation to learn, and anxiety. We also wanted to understand whether the proposed dimensions can be regarded as universal phenomena, less dependent on the field of studies or national education culture. This led us to formulate the following research questions:

Q1. Are the developed transparency tools reliable?

Q2. Are the dimensions of transparency invariant? Does the same underlying structure hold for perceptions of students from different universities?

Q3. Do students assess themselves as more transparent than peers?

Q4. Is perception of transparency associated with achievement? Do students who perceive dimensions of transparency more strongly, achieve higher grade average?

Q5. Is perception of transparency associated with motivation? Do students who perceive dimensions of transparency more strongly, attain higher intrinsic motivation to learn?

Q6. Is perception of transparency associated with anxiety? Do students who perceive dimensions of transparency more strongly, experience lower test anxiety?

Q7. Are any of the relationships mediated by another factor?

To answer these research questions, a questionnaire was administered to Italian and Russian university students in different faculties and disciplinary areas, to test the assumption that "transparency" is universal and interdisciplinary.

\section{Method}

\section{Procedure for questionnaire development}

The procedure used to develop the questionnaire consisted of three steps. First, we constructed a pool of questions based on our theoretical framework, describing the above three transparency dimensions: teacher, peer, self in each sphere - decisions, feedback, content. We used English version of the questionnaire, which at the second step was double blind translated into Russian and Italian by bilingual assistants; all inconsistencies were reformulated to achieve the same meaning of the questions. At the third step, the quality of the scales was assessed in a pilot study of 
Russian and Italian students [reference to authors]. All questions used in the survey (anxiety, motivation, etc.) were subjected to the same procedure. Finally, the revised version was examined in the presented study.

\section{Universities}

As the main aim of the study was to explore perception of transparency in different education environments, the questionnaire was distributed to students at Universities from two countries. As discussed earlier, Russia is usually regarded as less transparent or at least less democratic than EU countries. At the same time, leading Universities actively participate in the Bologna Process and exchange students. For example, Catholic University of the Sacred Heart of Milan has an exchange program with Research University Higher School of Economics in Russia; students can participate in double-diploma programs. Such exchange programs would guarantee a comparable quality of education.

Catholic University of the Sacred Heart (UNICATT) is the largest private university in Europe and has campuses in Milan, Rome, Brescia, Piacenza, and Cremona. National Research University Higher School of Economics (NRU HSE) is a public university and has campuses in Moscow, St. Petersburg, Nizhny Novgorod, and Perm. Although NRU HSE is a public University it has the authority to form educational agenda and develop its own educational standards. Both universities are well-established with a long history.

The University of Foggia (UNIFG) differs from the other two institutions in its origin, size, and regional reach. It was founded relatively recently in 1999, is medium-sized and its education caters to the needs of the territory. In recent years the University has developed several international research projects.

\section{Procedure}

Invitations were send by email to students of all three Universities (for UNICATT from its Milan campus, for NRU HSE from its Nizhny Novgorod campus, for UNIFG from its Foggia campus), all students were asked to use the provided link and participate in on-line survey. Data were collected using a professional subscription to the Survey Monkey service which allowed us to receive answers from Russian and Italian students located in different regions and guarantee equal conditions for participants. Prior to the study we provided students with full 
information about the research and they were able to quit the survey at any time. Participation was on a voluntary basis and students received no remuneration or course credits. Anonymity was preserved.

\section{Sample}

Two hundred and sixty-two students from the Higher School of Economics in Russia (Nizhny Novgorod campus), 128 from Catholic University of the Sacred Heart (Milan campus, Italy) and 40 students from the University of Foggia (Foggia campus). Participants were asked questions about their demographics, education, and social status: age, gender, faculty, year of entrance in the university, and family income.

Some of the respondents preferred not to answer the demographic questions: 9 (5\%) in the Italian and $124(47.32 \%)$ in the Russian sample. They were excluded from analyses relating transparency to demographic variables. In each country students belonged to different faculties and year of study. In the Russian sample the majority of participants were female (78.98\%), born in 1994-1995 (55\%), studying Economics (60.14\%); the rest of students were enrolled in Law (23.18\%), Management (15.94\%), and Psychology (0.07\%). The majority of Italian participants were female (83.33\%), born in 1991-1992 (42.26\%), studying Psychology $(76.19 \%)$; the remaining students were enrolled in Law $(16.66 \%)$, Medicine (6.54\%), and Economics (0.59\%).

\section{Average grade}

Average grade is a usual measure of learning outcomes. We asked students to report their average grade and categorized it into six levels according to the respective university systems of assessment (for Russia the interval was from 4 to 10 and for Italy from 18 to 30 ).

\section{Scales}

Unless otherwise noted, all scale-based variables were measured using a Likert-type response scale ranging from $1=$ strongly disagree to $5=$ strongly agree. The items were presented to participants in a random order. Items and descriptive statistics for the scales are presented in Appendix 1, Tab. 1-5. 


\section{Intrinsic Motivation Scale}

To investigate intrinsic motivation we used the scale devised by Author et al. (2012) based on Pintrich and colleagues' (1991) work. The scale includes five questions concerning different aspects of intrinsic interest in learning (e.g. "I prefer courses that really challenge me so I can learn new things"). The scale demonstrated good reliability for both samples (Russian $\alpha=.71$, Italian $\alpha=.72$ ).

\section{Anxiety Scale}

To investigate test anxiety we used the scale adapted from Pintrich and colleagues (1991) by Author et al. (2012). The scale includes five questions concerning different aspects of test anxiety (e.g. "I feel my heart beating fast when I take an exam"). There was good reliability for both samples (Russian $\alpha=.70$, Italian $\alpha=.71$ ).

\section{Teacher Transparency Scale}

The teacher transparency scale was created to investigate perception of average transparency within the study program in which respondents were enrolled with reference to decision making, feedback, and content. The scale consists of six questions (e.g. "Most teachers in my University are open to criticism by students"). Four questions were reversed (e.g. Most teachers in my University ignore students' opinions when making decisions). There was good reliability for both samples (Russian $\alpha=.77$, Italian $\alpha=.70$ ).

\section{Self Transparency Scale}

The scale was created to investigate perception of self-transparency of a student in decision making, feedback, and content. It consists of four questions (e.g. "In most courses I had finished I shared the class materials that I found in addition to standard course contents"). Scale reliability: Russian $\alpha=.72$, Italian $\alpha=.66$.

\section{Peer Transparency Scale}

The scale was created to investigate perception of peer transparency of a student on the same dimensions as the self-transparency and teacher transparency scales. It includes four questions (e.g "In most courses I had finished my mates shared the class materials they found in addition to standard course contents"). Scale reliability: Russian $\alpha=.80$, Italian $\alpha=.66$. 


\section{Analysis}

First we tested the reliability of all scales and invariance of the scales' structure in the Russian and Italian samples by computing $\alpha$-Cronbach coefficients and then by using structural equation modelling (analysis of covariance structure: COVS). We followed the usual procedure to test significance of shift using Wilcoxon test. To answer our main question about the influence of transparency on learning outcomes (grades), intrinsic motivation, and test anxiety we ran a series of linear regressions. To test the invariance of the influence of transparency on learning outcomes in the Russian and Italian samples we used structural equation modelling. All analyses were run through R (Core Team, 2017) using psych (Revelle, 2017), lavaan (Rosseel, 2012), semTools (SemTools Contributors, 2016), semPlot (Epskamp \& Stuber, 2017), and mediation (Tingley, Yamamoto, Hirose, Keele \& Imai, 2014) packages.

\section{Structural Equation Modelling}

The structural models for transparency dimensions and their relationship to intrinsic motivation, anxiety, and academic success (itemized scales presented in Appendix 1, Tables 1-5), are based on Figure 1. Analyses showed configural and loadings invariance (see Table 1). The loadings invariant model did not differ significantly from the configural model with delta CFI for loadings invariant model less than the suggested .01, demonstrating a good fit (CFI 0.858, TLI $=0.844$, RMSEA $=$. 057, 90\% C.I $=.049-0.064$, SRMSR $=0.068)$ and the lowest AIC (23851) and BIC (24422). Following Hu and Bentler (1999), who claimed that models with SRMSR value less than 0.08 are good fitted models, we can conclude that we observed structural invariance in our samples and so we can answer affirmatively Q2. As the intercepts, residuals and means invariance were not observed, for the subsequent comparisons of means we had to analyse samples separately.

We can see from the structural model that self-transparency was highly correlated with peer-transparency. This was expected since we usually estimate properties of others based on our own impressions. We also expected that students would overestimate their own transparency or, conversely, underestimate transparency of their peers (Q3). Analyses showed that our participants in Russia and Italy came from a population who has a non-normal distribution in the self-transparency scale (e.g., Shapiro-Wilk test in the Italian sample: $\mathrm{W}=0.961, \mathrm{p}<.001$ ) so we had to use non-parametric tests such as the Wilcoxon test. Wilcoxon signed rank test with continuity correction showed that true location shift is less 
than 0 (perceived self-transparency is greater than perceived peer-transparency) in the Italian sample $(\mathrm{V}=2921, \mathrm{p}=.003)$ and the Russian sample $(\mathrm{V}=6848, \mathrm{p}=.023)$, which leads us to answer affirmatively Q3.

Tab.1 - Measurement Invariance Models

\begin{tabular}{lccccccc}
\hline $\begin{array}{l}\text { Model with } \\
\text { invariance }\end{array}$ & Df & AIC & BIC & CFI & RMSEA & CFI.delta & RMSEA.delta \\
\hline Configural & 484 & 23864 & 24509 & 0.861 & 0.057 & NA & NA \\
Loadings & 503 & 23851 & 24422 & 0.858 & 0.057 & 0.003 & 0.000 \\
Intercepts & 522 & 24188 & 24683 & 0.692 & 0.082 & 0.165 & 0.025 \\
Residuals & 546 & 24249 & 24650 & 0.653 & 0.085 & 0.04 & 0.003 \\
Means & 551 & 24337 & 24718 & 0.609 & 0.09 & 0.043 & 0.005 \\
\hline
\end{tabular}

Next we moved to investigate how transparency influences learning outcomes. From the structural model we infer that transparency scales were positively correlated with intrinsic motivation and negatively with anxiety. To test our question we ran a series of linear regressions (see Tab. 2). We could see that male students had less test anxiety $(\beta=-0.52$, $\mathrm{p}<.001)$ and students with desire to have higher grades than peers had higher average grade $(\beta=0.3, p<.001)$. Conversely, students who avoid tasks had lower grades $(\beta=0.18, p=.006)$, were less intrinsically motivated and had higher anxiety $(\beta=0.1, p=.044)$. All other variables (country, income, birth year, year of entrance in university) were not significant. Regarding grades, we failed to observe any significant influence of transparency, thus the conjecture related to Q4 was not confirmed. Self-transparency influenced significantly intrinsic motivation $(\beta=0.26$, $\mathrm{p}<.001$ ), thus providing a positive answer to Q5. Teacher transparency decreased test anxiety $(\beta=-0.19, \mathrm{p}=.018)$, which provides support for Q6. 
Tab.2 - Models of Learning Outcomes (Insignificant Control Variables Removed to

\begin{tabular}{llllllll}
\multicolumn{1}{c}{ Keep Parsimony) } & & & & & \\
& Grade & & Intrinsic motivation & Anxiety & \\
& $\mathrm{B}$ & $\mathrm{p}$ & $\mathrm{B}$ & $\mathrm{P}$ & $\mathrm{B}$ & $\mathrm{p}$ \\
\hline (Intercept) & 4.14 & .008 & 1.19 & .256 & 4.56 & $<.001$ \\
Teacher Transparency & 0.17 & .112 & 0.13 & .064 & -0.19 & .013 \\
Peer Transparency & -0.15 & .175 & -0.07 & .329 & -0.11 & .165 \\
Self - Transparency & 0.17 & .142 & 0.28 & $<.001$ & 0.05 & .567 \\
Gender (male) & -0.31 & .091 & 0.05 & .650 & -0.52 & $<.001$ \\
Observations & 285 & & 282 & & 282 & \\
$\mathrm{R}^{2} /$ adj. $\mathrm{R}^{2}$ & $.274 / .176$ & $.205 / .096$ & & $.203 / .093$ \\
\hline
\end{tabular}

Although intrinsic motivation and anxiety can be results of teaching, they could also influence grades. Surprised by the result that grades were not influenced by transparency dimensions, we supposed that the influence of teacher transparency on grades was mediated by test anxiety (see Figure 2). To test this relationship we used the mediation procedure described by Tingley and colleagues (2014). The analysis supported the existence of a significant average causal mediation effect ( $\mathrm{p}<.001$, prop. mediated $=0.447$, see Fig. 2).

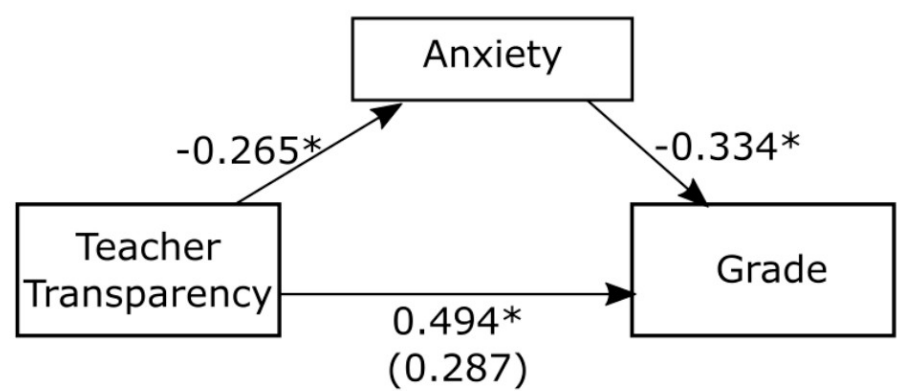

Fig.2 - Anxiety Mediation of Teacher Transparency Influence on Grade 


\section{Discussion}

In view of the lack of validated instruments to investigate perception of transparency in higher education, our first attempt was to devise a comprehensive tool to understand to what extent undergraduate students perceive that their university makes information, criteria, rules and procedures related to the curriculum visible. Based on the conceptualisation of "transparency" in the relevant literature, a broad set of items was generated, each describing an aspect which qualifies transparency in the university environment. In alignment with findings from the pilot version of the instrument [reference to authors], these items were grouped into three scales, related to perceptions of transparency in teachers', one's own, and peers' behaviour. Analyses supported the notion that the three transparency scales are valid and reliable. Items allowed to discriminate the degrees in which the underpinnings to educational activities are explicit to students and total scores can be used to measure the level of clarity of such underpinnings in students' perception.

Mean values, standard deviations and reliability coefficients were overall similar in the two subsamples and correlations matrices, as well as the outcomes of structural modelling. As a result, they failed to highlight differences between Russian and Italian students, which makes us conclude that country is not a factor affecting the perception of transparency. On the contrary, transparency appears to be a rather stable construct, independent from personal characteristics (age, gender, years of education, type of faculty attended, economic status) and socio-cultural environment. In fact, analyses revealed that the transparency scales have a good reliability and structural invariance across the Russian and Italian samples. Nevertheless, they would not provide possibility to compare directly values of transparency between both countries, as only structural invariance was observed.

Since the items of the self and peer transparency scales address the same issues, a direct comparison of how collaboration is perceived from the two sides was possible. We found that perceived self transparency was higher than peer transparency. Students appeared to believe that they are more engaged in the social exchange than their classmates. This might correspond to a general attitude as students have more information about themselves and less about their peers. It is also consistent with the findings of studies showing that the occurrence of actions performed by oneself is overestimated in comparison to the alleged frequency of the same actions performed by other people because of the availability heuristics (Peseta \& Amani, 2020). It is easy for an individual to retrieve in- 
stances of that action when executed by him/her but not by other persons because of the accessibility and impressionability of the autobiographical memory.

As for the relationships among transparency and grades, motivation, and anxiety, it appears that transparency is linked to intrinsic motivation and anxiety but not to grades. Presumably, when teaching and learning activities do not have aspects which are hidden to students, their engagement and sense of self-efficacy increase since they perceive the meaning of tasks and do not hesitate to go beyond formal requests of their teachers. This in turn deepens the content they are asked to acquire and allows them to master skills the tasks are intended to promote, thus developing self-regulation ability in their study. Furthermore, a transparent environment enables students to know in advance what they have to learn to pass the exams and the way they will be evaluated. As a consequence, they trust their examiners and are confident but not anxious about what might happen during the exams (Vanstone \& Hicks, 2019).

Modelling learning outcomes showed that self transparency influences intrinsic motivation and teacher transparency influences test anxiety. Surprisingly, peer transparency has no significant influence on learning outcomes. It is likely that being aware of the value of one's own learning processes leads students to appreciate the educational goals and adhere to them so that extra work is accepted and the will to enhance their competences prevails. Although the results of our research have underlined the positive influence of self transparency more than peer transparency on learning outcomes, findings about positive effects of cooperative learning exercises on the development of students' self-efficacy are undoubted (Dunbar, Dingel, Dame, Winchip \& Petzold, 2016; De Hei, Admiraal, Sjoer \& Strijbos, 2018). But we also found the effect of teacher transparency mediated by test anxiety, meaning that higher teacher transparency led to less test anxiety and higher grades.

\section{Limitations}

Our study has some limitations. Gender, age, faculties, university and country appeared not to be an influencing factor, but these were not balanced in the samples. Future studies may pay more attention to this aspect. Also the question of causality of the relationship between transparency, motivation and academic achievement warrants further investigation. The students-teachers ratio may also have an impact on transparency as well as the ratio of on-line vs off-line activities, but they do not vary much within the faculty. Since we found no significant effects of fa- 
culty, it is unlikely an important factor, although drastic changes in digitalization of Higher Education may lead to new challenges in the development of transparent learning environments.

In the samples, Russian students belong to the cohorts of 1994-1995, while Italian students belong to the cohorts of 1991-1992 due to differences in educational systems (in Russia students are usually pushed to receive higher education). But we found no significant age effect on perceived transparency, so it is unlikely that this bias in the sample would have an important effect on our results. The same relates to gender bias in our samples, which represents actual male/female ratios at faculties of respondents, but not in Russian or Italian population in general.

Despite these limits, the present investigation contributed to the availability of a reliable tool to investigate the perception of transparency in university context and to the understanding of factors which influence or fail to influence such perception. The presented study highlighted the impact that transparency may have on students' mental processes when engaged in learning as well as on their study outcomes.

\section{Educational Implications}

Our research has shown how "transparency" in university education favours the involvement of students in the definition of their learning objectives, allowing learning objectives to develop and change throughout a course or a longer learning trajectory (Dixon, Yssel, McConnel \& Hardin, 2014). Validating what the referent academic literature supports (Wollenschläger, Hattie, Macths, Möller \& Harms, 2016), our investigation has also shown how greater "transparency" in assessment practices contributes to limiting performance anxiety during university exams, thus preventing the onset of negative emotions dictated by uncertainty and fear. Furthermore, no significant differences emerged in the perception of transparency between Italian and Russian students, highlighting its universal nature that transcends culture, country, faculty, and disciplinary area.

The present study has significant implications for educational practice. Increasing "transparency" in an educational institution contributes not only to a higher level of students' willingness to learn and improve their skills; it also allows students to feel better during the time they spend in such institution and leads to better academic outcomes. It is possible to speak of academic success only when students, in addition to acquiring a series of notions through "transparent" educational practices, are able to ask for help in times of difficulty. This in turn helps them to develop a greater sense of belonging to the institution, greater motivation 
to study and the ability to self-regulate their learning (Duchatelet \& Donche, 2019; Won, Hensley \& Wolters, 2019). Moreover, the presence of greater transparency in university teaching/learning processes would help teachers to become aware of the effectiveness of their teaching methods and, in case of ineffectiveness, it would help them to intervene in time, in order to make improvements in the quality of their teaching or communication with students. Communication has been considered by several scholars as the foundation of the teaching process (Ligozat \& Almqvist, 2018). In fact, communication based on the principles of transparency can help students to develop self-efficacy skills that will be also useful in their future workplace (Çetin \& Aşkun, 2018). Finally, we believe that the tool we have developed to capture effects of perceived "transparency", if used together with other qualitative investigative tools, can have significant educational implications, as it helps teachers to better understand their relationship with students and allows students to reflect on themselves, their skills and training needs. Through the knowledge that derives from the investigation of "transparency" in educational practices, it is in fact possible to plan learning paths in which students, as envisaged by the Bologna Process, are the main protagonists. Perception of transparency could therefore be considered a useful educational dimension to encourage peer learning, collaboration between teachers and students, in order to strengthen the sense of self-efficacy of those who learn.

\section{References}

Bologna Declaration (1999). The European Higher Education Area. http://www.ehea.info/media.ehea.info/file/Ministerial_conferences/02/8/199 9_Bologna_Declaration_English_553028.pdf.

Byl, E., Struyven, K., Meürs, P., Ābelshausen B., Vanwing T., Engels N., \& Lombaerts, K. (2016). The value of peer learning for first-year postgraduate university students' social and academic integration. Procedia - Social and Behavioral Sciences, 228, 299-304. DOI: 10.1016/j.sbspro.2016.07.044.

Çetin, F. H., \& Askun, D. (2018). The effect of occupational self-efficacy on work performance through intrinsic work motivation. Management Research Review, 41(2), 186-201.

Cohen, P. A. (1980). Effectiveness of student-rating feedback for improving college instruction: A meta-analysis of findings. Research in Higher Education, 13(4), 321-41. DOI: 10.1007/BF00976252.

Core Team, R. (2017). R: A language and environment for statistical computing. R Foundation for Statistical Computing, https://www.R-project.org/.

De Hei, M., Admiraal, W., Sjoer, E., \& Strijbos, J-W. (2018). Group learning activities and perceived learning outcomes. Studies in Higher Education, 43(12), 2354-2370. DOI: 10.1080/03075079.2017.1327518. 
Dixon, F. A., Yssel, N., McConnel, J. M., \& Hardin, T. (2014). Differentiated instruction, professional development, and teacher efficacy. Journal for the Education of the Gifted, 37(2), 111-127. DOI: 10.1177/0162353214529042.

Duchatelet, D., \& Donche, V. (2019). Fostering self-efficacy and self-regulation in higher education: A matter of autonomy support or academic motivation? Higher Education Research \& Development, 38(4), 733-747. DOI: 10.1080/07294360.2019.1581143.

Dunbar, R. L., Dingel, M. J., Dame, L. F., Winchip, J., \& Petzold, A. M. (2016). Student social self-efficacy, leadership status, and academic performance in collaborative learning environments. Studies in Higher Education, 43(9), 1507-1523. DOI: 10.1080/03075079.2016.1265496.

Dunlosky, J., \& Metcalfe, J. (2009). Metacognition. Thousand Oaks, CA: Sage Publications.

Ellis, S., \& Tod, J. (2014). Promoting behaviour for learning in the classroom. New York, NY: Routledge.

Epskamp, S., \& Stuber, S. (2017). SemPlot: Path diagrams and visual analysis of various SEM packages' output. R package version 1(1). https://CRAN.Rproject.org/package $=$ semPlot.

European Commission/EACEA/Eurydice (2018). The European Higher Education Area in 2018 . https://eacea.ec.europa.eu/nationalpolicies/eurydice/sites/eurydice/files/bologna internet 0.pdf.

Gavrilyuk, O. A., Nosova, L. G., Susloparova, R., \& Lakhno, A. V. (2015). University autonomy and teacher's academic freedom in modern Russia: Challenges and opportunities. International Journal of Humanities Social Sciences and Education (IJHSSE), 2(10), 8-15.

Hattie, J. (2012). Visible learning for teachers: Maximizing impact on learning. New York, NY: Routledge.

Hattie, J., \& Yates, G. (2014). Visible learning and the science of how we learn. New York, NY: Routledge.

Howard, T. O., Winkelmes, M-A., \& Shegog, M. (2020). Transparency teaching in the virtual classroom: Assessing the opportunities and challenges of integrating transparency Teaching methods with online learning. Journal of Political Science Education, 16(2), 198-211. D O I: 10.1080/15512169.2018.1550420.

HRV Transparency index (2010). Our world in data. https://ourworldindata.org/grapher/hrv-transparency-index.

Hu, L-t., \& Bentler, P. M. (1999). Cutoff criteria for fit indexes in covariance structure analysis: Conventional criteria versus new alternatives. Structural Equation Modeling, 6(1), 1-55. DOI: 10.1080/10705519909540118.

Jones, B. D., \& Carter, D. (2019). Relationships between students' course perceptions, engagement, and learning. Social Psychology of Education: An International Journal, 22(4), 819-839.

Jönsson, A., \& Balan, A. (2017). Effects on student motivation and performance by increased transparency in assessment: EARLI-konferensen [Paper presentation]. Tampere, Finland: Biennial Conference of the EARLY, http://www.divaportal.org/smash/record.jsfpid=diva2\%3A1238545\&dswid=8076. 
Jönsson, A., \& Prins, F. (2019). Editorial: Transparency in assessment-exploring the influence of explicit assessment criteria. Frontiers in Education, 3(119). DOI: $10.3389 /$ feduc.2018.00119.

Jurkowski, S., \& Hänze, M. (2015). How to increase the benefits of cooperation: Effects of training in transactive communication on cooperative learning. British Journal of Educational Psychology, 85(3), 357-371. DOI: 10.1111/bjep.12077.

Karavaeva, E., \& Zapryagaev, E. (2015). Integration of Russian higher education system in EHEA. Problems and achievements. EIRP Proceedings, Vol. 10. http://www.proceedings.univdanubius.ro/index.php/eirp/article/view/158 6/1557.

Karpouza, E., \& Emvalotis, A. (2019). Exploring the teacher-student relationship in graduate education: A constructivist grounded theory. Teaching in Higher Education, 24(2), 121-140. DOI: 10.1080/13562517.2018.1468319.

Lennon, S., Riley, T., \& Monk, S. (2018). The uncomfortable teacher-student encounter and what comes to matter. Teaching in Higher Education, 23(5), 619-630. DOI: 10.1080/13562517.2018.1458711.

Ligozat, F., \& Almqvist, J. (2018). Conceptual frameworks in didactics and teaching: Trends, evolutions and comparative challenges. European Educational Research Journal, 17(1), 3-16. DOI: 10.1177/1474904117746720.

Loes, C. N., \& Pascarella, E. T. (2017). Collaborative learning and critical thinking: Testing the link. The Journal of Higher Education, 88(5), 726-753. DOI: $10.1080 / 00221546.2017 .1291257$.

Pandero, E., \& Jönsson, A. (2013). The use of scoring rubrics for formative assessment purposes revisited: A review. Educational Research Review, 9, 129-144. DOI: 10.1016/j.edurev.2013.01.002.

Pasupathy, R., \& Siwatu, K. O. (2014). An investigation of research self-efficacy beliefs and research productivity among faculty members at an emerging research university in the USA. Higher Education Research and Development, 33(4), 728-41. DOI: 10.1080/07294360.2013.863843.

Peseta, T., \& Amani, B. (2020). "Seeing institutionally": A rationale for 'teach the university' in student and staff partnerships. Higher Education Research and Development, 39(1), 99-112. DOI: 10.1080/07294360.2019.1676200.

Pintrich, P. R., Smith, D. A. F. T., Duncan, T., \& McKeachie, W. J. (1991). A manual for the use of the motivated strategies for learning questionnaire (MSLQ). University of Michigan, National Center for Research to Improve Postsecondary Teaching and Learning. http://www.eric.ed.gov/contentdelivery/servlet/ERICServlet?accno=ED338122.

Revelle, W. R. (2017). Procedures for personality and psychological research. Northwestern University. https://CRAN.R-project.org/package=psych Version $=1.7 .8$.

Romanova, G., Romanov, M., Maznichenko, M., \& Oborin, M. (2018). Realization of student academic rights towards the Bologna Process: Challenges and solutions. The European Proceedings of Social \& Behavioural Sciences, 324-336. DOI: 10.15405/epsbs.2018.12.02.35. 
Rosseel, Y. (2012). Lavaan: An R package for structural equation modelling. Journal of Statistical Software, 48(2), 1-36. http://www.jstatsoft.org/v48/i02/.

SemTools Contributors. (2016). SemTools: Useful tools for structural equation modeling. R Package Version 0.4-14. http://cran.rproject.org/web/packages/semTools/index.html.

Tingley, D., Yamamoto, T., Hirose, K., Keele, L., \& Imai, K. (2014). Mediation: R package for causal mediation analysis. Journal of Statistical Software, 59(5), 1-38. http://www.jstatsoft.org/v59/i05/.

Tinto, V. (1993). Leaving college: Rethinking the causes and cures of student attrition (2nd.ed). Chicago, IL: University of Chicago Press.

Vanstone, D. M., \& Hicks, R .E. (2019). Transitioning to university: Coping styles as mediators between adaptive-maladaptive perfectionism and test anxiety. Personality and Individual Differences, 141, 68-75. DOI: 10.1016/J.paid.2018.12.026.

Winkelmes, M.-A., Copeland, D. E., Jorgensen, E., Sloat, A., Smedley, A., Pizor, P., Jhnson, K., \& Jalene, S. (2015). Benefits (some unexpected) of transparently designed assignments. National Teaching \& Learning Forum, 24(4), 4-7. DOI: 10.1002/ntlf.30029.

Winkelmes, M.-A. (2016). Helping faculty use assessment data to provide more equitable learning experiences. University of Illinois and Indiana University, National Institute for Learning Outcomes Assessment. https://blogs.illinois.edu/view/915/340096.

Winkelmes, M.-A., Boye, A., \& Tapp, S. (2019). Transparent design in higher education teaching and leadership: A guide to implementing the transparency framework institution-wide to improve learning and retention. Sterling, VA: Stylus Publishing, LLC.

Wollenschläger, M., Hattie, J., Macths, N., Möller, J., \& Harms, U. (2016). What makes rubrics effective in teacher feedback? Transparency of learning goals is not enough. Contemporary Educational Psychology, 44-45, 1-11. DOI: 10.1016/J.cedpsych.2015.11.003.

Won, S., Hensley, L. C., \& Wolters, C. A. (2019). Brief research report: Sense of belonging and academic help-seeking as self-regulated learning. The Journal of Experimental Education. DOI: 10.1080/00220973.2019.1703095.

Yefimov, V. S. (2012). The future of the higher school in Russia: Expert opinion. Foresight research - 2030. Krasnojarsk: Siberian Federal University. 


\section{Appendix 1}

Tab.1 - Means (M) and Standard Deviations (SD) of the Intrinsic Motivation Scale

\begin{tabular}{|c|c|c|c|c|}
\hline \multirow[t]{2}{*}{ Item } & \multicolumn{2}{|c|}{ Russia } & \multicolumn{2}{|c|}{ Italy } \\
\hline & M & $\mathrm{SD}$ & M & SD \\
\hline I prefer courses that really challenge me so I can learn new things & 3.2 & 0.90 & 3.8 & 0.93 \\
\hline \multicolumn{5}{|l|}{ There are courses I am so interested in that I continue studying even } \\
\hline if I have to work more than necessary & 3.1 & 1.10 & 3.3 & 1.13 \\
\hline \multicolumn{5}{|l|}{ Some tasks provide me such a pleasure that I want to spend more } \\
\hline time doing them than is necessary for the exam & 3.9 & 0.97 & 3.2 & 1.12 \\
\hline \multicolumn{5}{|l|}{ If I have a choice between creative exercise and standard one I pre- } \\
\hline fer the creative, even if it could be more complicated & 3.4 & 1.11 & 3.7 & 1.10 \\
\hline \multicolumn{5}{|l|}{ When I have the opportunity in this class, I choose assignments whe- } \\
\hline re I can learn new things, even if they do not guarantee a good grade & 3.3 & 0.90 & 3.7 & 0.91 \\
\hline Total score & 3.4 & 0.68 & 3.5 & 0.72 \\
\hline
\end{tabular}

Tab.2 - Means (M) and Standard Deviations (SD) of the Test Anxiety Scale

\begin{tabular}{llllll}
\hline Item & Russia & & Italy & \\
& M & SD & M & SD \\
\hline
\end{tabular}

When I take a test I think about how poorly I am doing compared

$\begin{array}{lllll}\text { with other students } & 3.0 & 1.1 & 2.1 & 1.1\end{array}$

When I take a test I think about items on other parts of the test I

$\begin{array}{lcccc}\text { can't answer } & 3.3 & 1.0 & 2.8 & 1.1 \\ \text { When I take tests I think of the consequences of failing } & 3.3 & 1.2 & 3.6 & 1.2 \\ \text { I have an uneasy, upset feeling when I take an exam } & 3.6 & 1.0 & 3.4 & 1.2 \\ \text { I feel my heart beating fast when I take an exam } & 3.7 & 1.1 & 3.9 & 1.1 \\ \text { When I take a test I think about how poorly I am doing compared } & & & \\ \text { with other students } & 3.0 & 1.1 & 2.1 & 1.1 \\ \text { Total score } & 3.4 & 0.74 & 3.2 & 0.79\end{array}$


Tab.3 - Descriptive Statistics for the Teacher Transparency Scale Items

\begin{tabular}{|c|c|c|c|c|}
\hline \multirow{2}{*}{$\begin{array}{l}\text { Item } \\
\text { Most teachers in my University ... }\end{array}$} & \multicolumn{2}{|c|}{ Russia } & \multicolumn{2}{|c|}{ Italy } \\
\hline & $\mathrm{M}$ & SD & $\mathrm{M}$ & $\mathrm{SD}$ \\
\hline Ignore students' opinions when making decisions (reversed) & 3.5 & 0.86 & 3.6 & 1.05 \\
\hline Are open to criticism by students & 2.6 & 0.94 & 3.2 & 0.87 \\
\hline \multicolumn{5}{|l|}{ Provide only final grades and it is hard to understand why I recei- } \\
\hline ved that grade (reversed) & 3.4 & 0.90 & 3.8 & 0.90 \\
\hline Ignore students' needs and personal strivings (reversed) & 3.4 & 0.80 & 3.2 & 0.89 \\
\hline \multicolumn{5}{|l|}{ Provide information in a way which makes it difficult to under- } \\
\hline stand (reversed) & 3.5 & 0.86 & 3.6 & 1.03 \\
\hline \multicolumn{5}{|l|}{ Establish connections between notions and theories within the } \\
\hline course or between courses & 3.4 & 1.00 & 3.7 & 0.93 \\
\hline Total score & 3.5 & 0.60 & 3.3 & 0.62 \\
\hline
\end{tabular}

Tab.4 - Descriptive Statistics for the Self Transparency Scale Items

\begin{tabular}{|c|c|c|c|c|}
\hline \multirow{2}{*}{$\begin{array}{l}\text { Item } \\
\text { In most courses I had finished ... }\end{array}$} & \multicolumn{2}{|c|}{ Russia } & \multicolumn{2}{|l|}{ Italy } \\
\hline & $\mathrm{M}$ & SD & M & $\mathrm{SD}$ \\
\hline \multicolumn{5}{|c|}{ I shared the class materials that I found in addition to standard } \\
\hline course contents & 3.2 & 1.06 & 3.1 & 1.27 \\
\hline \multicolumn{5}{|c|}{ I provided my course mates with useful information about their } \\
\hline successes and failures & 2.9 & 0.94 & 3.8 & 0.85 \\
\hline \multicolumn{5}{|c|}{ I was open to criticism and ready to discuss my mistakes with my } \\
\hline course mates & 3.2 & 1.06 & 4.0 & 0.74 \\
\hline I shared my goals and my strivings in the class & 3.1 & 1.03 & 3.9 & 0.97 \\
\hline Total score & 3.1 & 0.76 & 3.7 & 0.69 \\
\hline
\end{tabular}


Tab.5 - Descriptive Statistics for the Peer Transparency Scale

Russia Italy

In most courses I had finished my mates...

$M \quad$ SD $\quad M \quad$ SD

Shared the class materials they found in addition to standard cour-

se contents

$\begin{array}{llll}3.1 & 1.13 & 3.2 & 1.08\end{array}$

Provided me with useful information about my successes and fai-

$\begin{array}{lcccc}\text { lures } & 2.9 & 0.97 & 3.7 & 0.87 \\ \text { Were open to criticism and ready to discuss their mistakes } & 3.0 & 0.99 & 3.6 & 0.85 \\ \text { Shared their goals and strivings in the class } & 3.1 & 1.07 & 3.8 & 0.80 \\ \text { Total score } & 3.0 & 0.82 & 3.6 & 0.64\end{array}$

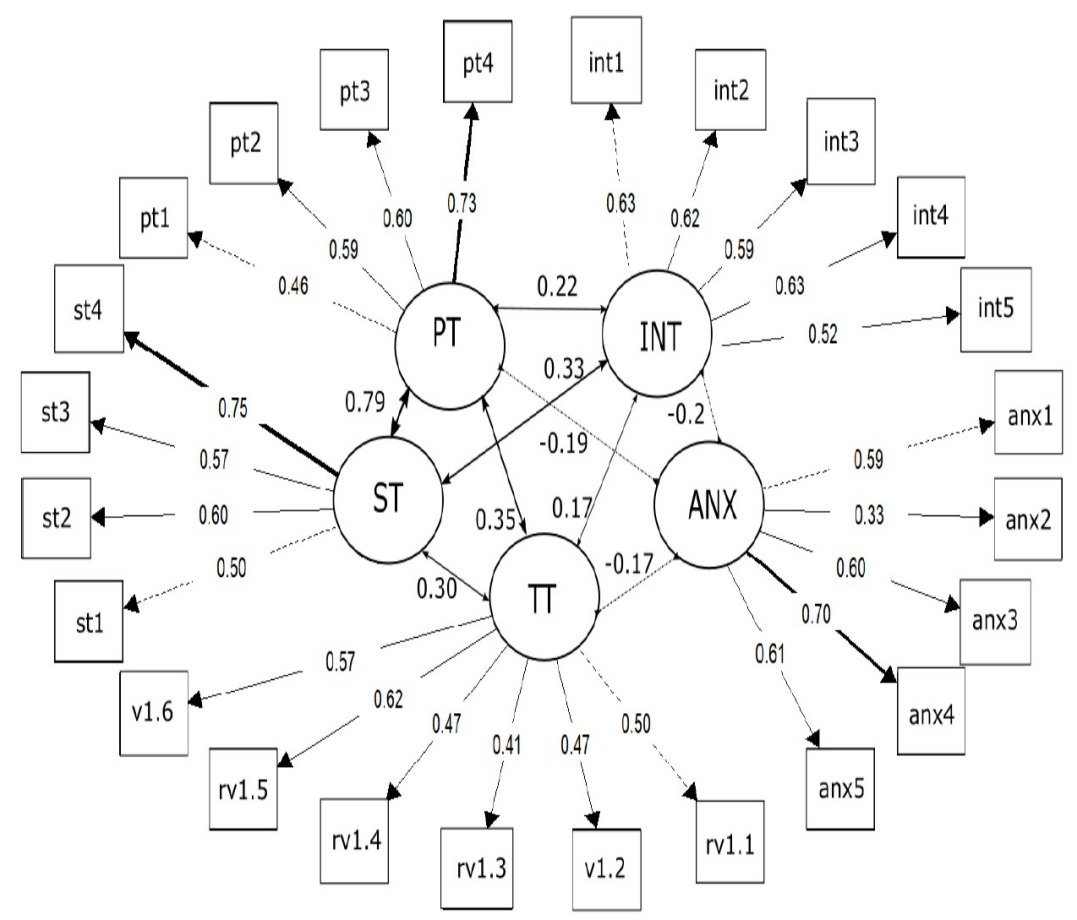

Fig.1 - Structural Model: Learning Outcomes and Transparency Dimensions 